\title{
Predictors of Physical Restraint Use in Hospitalized Veterans at End of Life: An Analysis of Data from the BEACON Trial
}

\author{
Elizabeth Kvale, $\mathrm{MD}^{1,2} \mathrm{~J}$. Nicholas Dionne-Odom, $\mathrm{PhD}, \mathrm{RN},{ }^{3}$ David T. Redden, $\mathrm{PhD}, 1,4$ \\ F. Amos Bailey, MD, ${ }^{1,2}$ Marie Bakitas, DNSc, CRNP, ${ }^{1,3}$ Patricia S. Goode, MSN, MD, ${ }^{1,2}$ \\ Beverly R. Williams, PhD, ${ }^{1,2}$ Kathlyn Sue Haddock, RN, PhD, and Kathryn L. Burgio, PhD ${ }^{1,2}$
}

\begin{abstract}
Background: The use of physical restraints in dying patients may be a source of suffering and loss of dignity. Little is known about the prevalence or predictors for restraint use at end of life in the hospital setting.

Objective: The objective was to determine the prevalence and predictors of physical restraint use at the time of death in hospitalized adults.

Methods: Secondary analysis was performed on data from the "Best Practices for End-of-Life Care for Our Nation's Veterans" (BEACON) trial conducted between 2005 and 2011. Medical record data were abstracted from six Veterans Administration Medical Centers (VAMCs). Data on processes of care in the last seven days of life were abstracted from the medical records of 5476 who died in the six VAMCs. We prospectively identified potential risk factors for restraint use at the time of death from among the variables measured in the parent trial, including location of death, medications administered, nasogastric tube, intravenous (IV) fluids, family presence, and receipt of a palliative care consultation.

Results: Physical restraint use at time of death was documented in 890 decedents (16.3\%). Restraint use varied by location of death, with patients in intensive settings being at higher risk. Restraint use was significantly more likely in patients with a nasogastric tube and those receiving IV fluids, benzodiazepines, or antipsychotics.

Conclusions: This is the first study to document that one in six hospitalized veterans were restrained at the time of death and to identify predictors of restraint use. Further research is needed to identify intervention opportunities.
\end{abstract}

\section{Introduction}

$\mathbf{T}$ he Centers for Medicare and Medicaid Services define physical restraint as "any manual method, physical or mechanical device, material, or equipment that immobilizes or reduces the ability of a patient to move his or her arms, legs, body, or head freely."1 Physical restraints can include belts, mittens, vests, bedrails, geriatric chairs, and other mechanical devices. The use of physical restraints in hospitalized patients is permissible only to prevent patients from harming themselves or others, and then only after lessrestrictive methods have been attempted. ${ }^{2}$
Clinical rationales for physical restraint use focus on protection of the patient and include concerns about disruption of necessary therapy, infliction of harm to oneself or others, and occurrence of falls. ${ }^{3}$ However, evidence suggests that physical restraints do not have these beneficial effects. ${ }^{4,5}$ In fact, restraint use has been associated with negative patient outcomes, including increased risk of delirium and agitation, ${ }^{6,7}$ pressure ulcers, ${ }^{8,9}$ falls, ${ }^{5,8,10}$ contractures, ${ }^{8,9}$ lengthened hospital stay, ${ }^{11}$ and death. ${ }^{9,12}$ Often, their use is a source of moral distress for family members and professional staff. $^{13,14}$ Older adult patients generally report being traumatized and depersonalized by the use of physical restraints,

\footnotetext{
${ }^{1}$ Department of Veterans Affairs, Birmingham/Atlanta Geriatric Research, Education, and Clinical Center, Birmingham VA Medical Center, Birmingham, Alabama.

${ }^{2}$ Center for Palliative and Supportive Care, ${ }^{3}$ School of Nursing, ${ }^{4}$ Department of Biostatistics, University of Alabama at Birmingham, Birmingham, Alabama.

${ }^{5}$ William Jennings Bryan Dorn VA Medical Center, Columbia, South Carolina.

Accepted February 1, 2015.
} 
and in some studies family members expressed similar concerns. $^{15,16}$

Although physical restraints have been utilized in patient care for more than a century, ${ }^{17}$ little is known about the prevalence of their use among actively dying patients in acute care settings. In 1986 Frengley and Mion, et al. reported that restrained patients accounted for nearly $50 \%$ of deaths among geriatric inpatients during the study's observation period, and attributed this finding to an association between restraint use and "severity of illness.", 18 A 1998 chart audit study in two hospitals found that one-fifth of decedents observed were physically restrained in the last two days of life. ${ }^{19}$ In intervening years, one would anticipate that regulatory forces and growing awareness of palliative and comfort care principles would reduce the likelihood of restraint use at the end of life. However, no subsequent studies were identified that reported on this issue. A direct observation study of processes of care in U.S. hospitals showed physical restraints were used in an average of 50 patient days out of every $1000 ;{ }^{20}$ however, numbers of patients who died in restraints were not reported.

A number of variables have been associated with the use of physical restraints in hospitalized patients, including patient factors, staffing factors, and setting factors. ${ }^{3,9,21-23,24} \mathrm{Re}-$ search consistently shows that physical restraint use is related to the site of care, with the highest rates reported in adult intensive care units (ICUs). ${ }^{20,25}$ Since one in five patients die in the ICU, ${ }^{26}$ it is likely that a significant proportion of patients could be spending their last days of life in physical restraints.

Given the limited information about this potential source of suffering in terminally ill patients, we sought to describe the prevalence and predictors of restraint use at the time of death. Identifying potentially modifiable factors may indicate potential targets for development of interventions to reduce restraint use in this vulnerable population.

\section{Methods}

We conducted a secondary analysis of data from the "Best Practices for End-of-Life Care for Our Nation's Veterans", (BEACON) trial, which is described elsewhere. ${ }^{27,28}$ Briefly, BEACON was a pragmatic, multisite implementation trial to evaluate the impact of an educational intervention on end-oflife care processes in six VA Medical Centers (VAMCs). The intervention included training inpatient staff to identify actively dying patients and to implement home hospice best practices in the acute care setting. Training was supported with educational resources, including pocket card decision support tools and an electronic comfort care order set. The intervention also facilitated policy changes to ensure availability of palliative care clinical interventions. The study was approved by the institutional review boards of the coordinating site and all participating clinical sites.

\section{Sample and cata collection}

During the study period (January 2005 through February 2011), medical records were abstracted for 6066 veterans who died in the six participating VAMCs during the pre- or post- intervention periods. Using a chart abstraction tool designed for the study, a registered nurse derived data from the decedents' electronic and paper records on the processes of care during the last seven days of life. Interrater reliability for the primary outcome measures was established between the chart abstractor and the director of palliative care at the coordinating center. For the purpose of this analysis we excluded the records of 590 veterans who died within a nursing home unit, leaving a sample of 5476 decedent records.

From the variables available in the database we selected potential predictors based on literature review and clinical experience. Predictors included location of death, medications administered (e.g., benzodiazepine, opioids, etc.), presence of nasogastric tube, IV fluids infusing, family presence at time of death, and palliative care consultation during the last seven days of life. Restraint use at time of death was operationalized as the documentation of an active order for restraints present in the electronic medical record at the moment of death. VAMC policy requires an active order for use of physical restraints. Demographic data (age, gender, race/ethnicity, and income) were obtained from the VA National Datasets.

\section{Statistical analysis}

Data from the six sites were pooled. To account for the clustered nature of the observations (patients nested within hospitals), generalized estimating equations (GEE) were used. $^{29}$ Initial statistical analyses estimated the association between the restraint use and the hypothesized predictors: location of death, medications administered, presence of nasogastric tube, IV fluids infusing at time of death, family presence, and palliative care consultation. For these preliminary analyses, we controlled for other variables that also might explain the variation in restraint use: the year of study, whether the observation was made before or after the intervention, and whether the patient had a diagnosis of anxiety or agitation. Careful adjustment of the degrees of freedom was conducted to account for the known issues of using GEE with small numbers of clusters. ${ }^{29-33}$

All predictors that achieved a significance level of 0.10 in the initial analyses were included in a multivariable modeling approach. Specifically, to account for the correlation among the predictors and to provide a final model, an iterative backward elimination approach was used in which the predictor with the largest $p$-value was removed. This iterative process continued until all remaining predictors reached a significance level of 0.05. Data were analyzed using statistical software SAS (SAS version 9.3, SAS Institute., Cary, NC).

\section{Results}

\section{Characteristics of the sample}

The characteristics of the sample are presented in Table 1. The sample was predominantly male (98\%) and white $(58 \%)$ or African American (31\%), with a mean age of 70.4 years. The most common terminal conditions were cancer $(30 \%)$ and heart disease $(20 \%)$. In 890 cases $(16.3 \%)$, the patient was in restraints at the time of death; $65 \%$ of patients who died in restraints were in an intensive care setting (ICU or surgical ICU), representing $24 \%$ of all ICU patients.

\section{Predictors of physical restraint use}

Bivariate analyses of predictors of restraint use at the time of death are presented in Table 2 and depicted in a forest plot 
Table 1. Sample Characteristics $(\mathrm{N}=5476)^{*}$

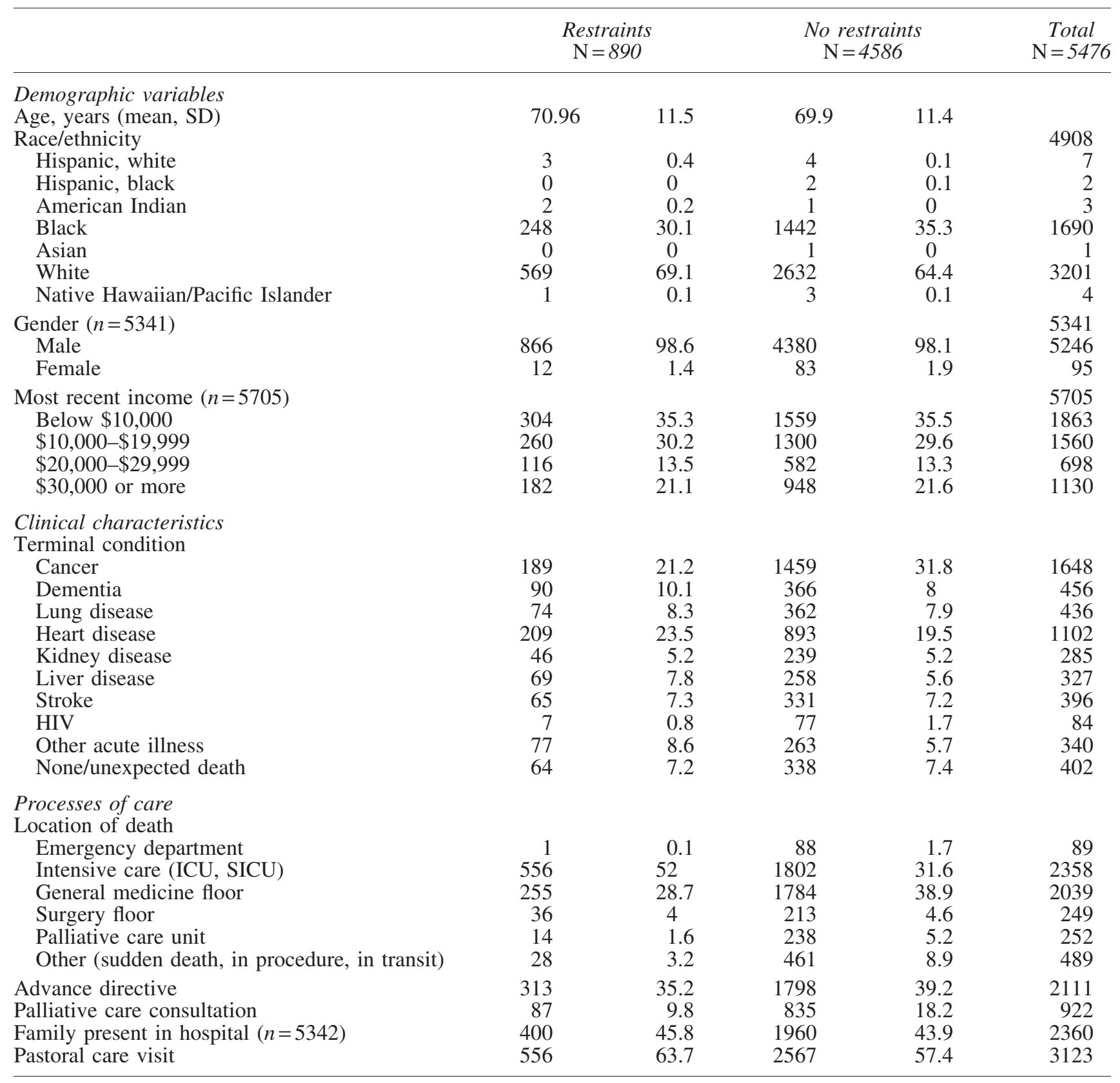

*Between groups $p$-values not meaningful because parent study was a stepwedge design cluster analysis with data influenced by site and time in a manner that cannot be adequately controlled for in this analysis.

in Figure 1. Bivariate analyses demonstrated a significant association between restraint use at the time of death and the ICU location of death; presence of a nasogastric tube; IV fluids; and administration of benzodiazepines, antipsychotics, or corticosteroids. Factors negatively associated with restraint use at the time of death were receiving a palliative care consultation and administration of death rattle medications. Opioid administration and family presence were not associated with restraint use.

In the final multivariable model, ICU location of death, nasogastric tube, IV fluids, and administration of an anti- psychotic or benzodiazepine remained significantly associated with restraints (see Table 3).

\section{Discussion}

The results of this analysis show that one in six veterans who died in the inpatient setting were restrained at the time of death. Restraint use was associated with presence of a nasogastric tube, IV fluids, use of an antipsychotic or benzodiazepine medication, and death in an intensive care setting. 
Table 2. Association between Restraint Use at Time of Death and Predictors: Bivariate Analysis ${ }^{a}$

\begin{tabular}{lccr}
\hline Predictor & Odds ratio & 95\% confidence interval & p-value \\
\hline Nasogastric tube & 3.13 & $(2.56,3.84)$ & $<0.0001$ \\
Intravenous fluids infusing & 3.02 & $(2.21,4.11)$ & $<0.0001$ \\
Intensive care unit & 2.85 & $(1.81,4.47)$ & $<0.0001$ \\
Benzodiazepine administered & 2.25 & $(1.87,2.71)$ & $<0.0001$ \\
Antipsychotic administered & 1.97 & $(1.50,2.58)$ & $<0.0001$ \\
Palliative care consultation & 0.66 & $(0.47,0.95)$ & 0.0231 \\
Corticosteroid administered & 1.24 & $(1.04,1.60)$ & 0.0566 \\
Family presence & 1.11 & $(0.98,1.25)$ & 0.0905 \\
Opioid administered & 0.97 & $(0.59,1.18)$ & 0.7761 \\
Medication for death rattle administered & 0.78 & 0.0865 & \\
\hline
\end{tabular}

${ }^{a}$ All models controlled for year of observation, intervention period, and presence of anxiety or agitation.

Invasive medical treatments like nasogastric tubes and IV fluids previously have been reported to be associated with agitated and disruptive behavior. ${ }^{34}$ While these interventions may have a role in symptom management, other, lessintrusive palliative management strategies often are available, such as medical management of intestinal obstruction and sublingual medication administration. The use of nasogastric tubes and IV lines may reflect family preference for lifesustaining treatments or may represent staff or family lack of awareness that the patient's death may be imminent.

There are a number of plausible explanations for the association between the use of restraints and use of antipsychotics and benzodiazepines at end of life. First, these medication classes have been associated with the development and perpetuation of delirium and disruptive behaviors in older adults, ${ }^{35,36}$ which can lead to physical restraint use. Second, these medications can be indicated to manage terminal delirium; therefore the association may reflect the appropriate management of delirium. ${ }^{37}$ And third, it is possible that these medications were a component of a prehospitalization management plan treating preexisting disruptive behaviors that invariably worsen in the hospital and decline in health and function. The study design did not allow us to evaluate whether some proportion of the decedents in this study were "appropriately" restrained to avoid harm to self and others when less-invasive interventions had failed.

Our finding that patients in an intensive care unit were 1.7 times as likely as other hospitalized patients to be restrained at time of death is consistent with previous studies demonstrating higher prevalence of restraint use in intensive settings. With $22 \%$ of deaths occurring in intensive settings, ICU admission has been likened to a "therapeutic trial" of maximal support, with a tradeoff in compromised quality of life as a potentially acceptable risk. ${ }^{38}$ ICU therapies that could be disrupted by an agitated patient, such as ventilator support, arterial lines, IV lines, nasogastric tubes, and bladder catheterization, may contribute to the rate of restraint use. If the "therapeutic trial" of ICU care is judged to be not effective or the burden of treatment greater than the benefit, prompt discontinuation of burdensome and iatrogenic harmful interventions should be insured with possible transfer from ICU to a setting more focused on comfort and support and that provides better access for family at the end of life. The proposed Quality Indicators for End of Life Care in the Intensive Care Unit do not address these issues explicitly, nor is the use of physical restraints at the end of life addressed

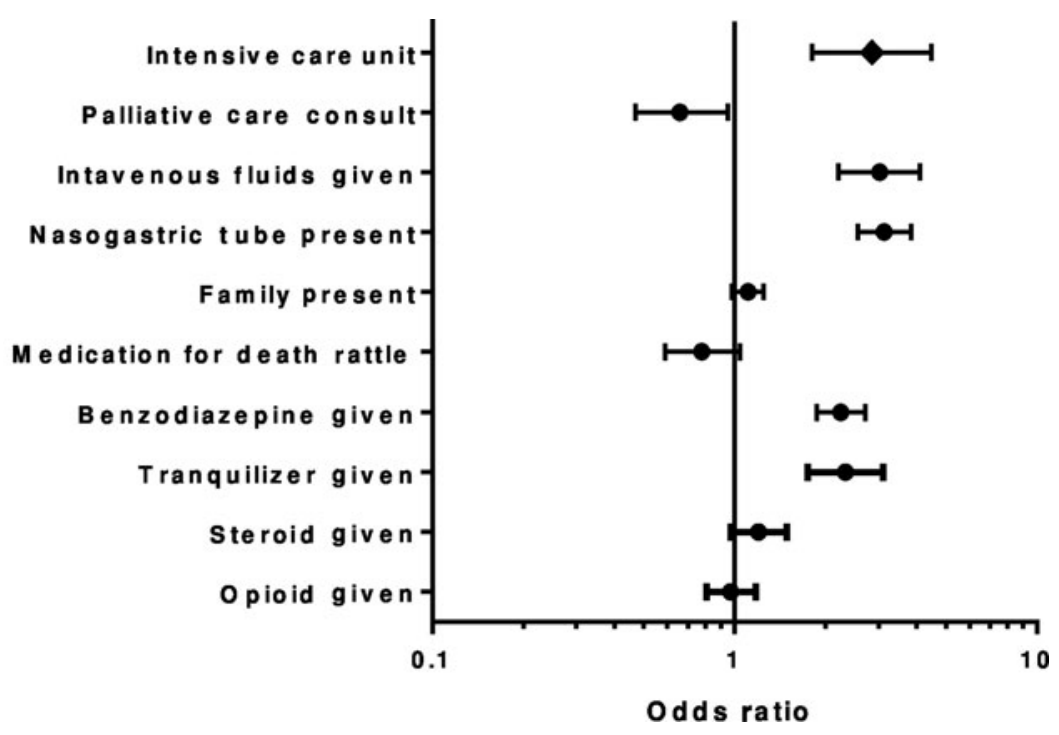

FIG. 1. Forest plot of odds ratio for restraint use with exposure to variable. 
Table 3. Association between Restraint Use at Time of Death and Predictors: Multivariable Analysis ${ }^{\mathrm{a}}$

\begin{tabular}{|c|c|c|c|}
\hline Predictor & $\begin{array}{l}\text { Odds } \\
\text { ratio }\end{array}$ & $\begin{array}{l}95 \% \text { Confidence } \\
\text { interval }\end{array}$ & p-value \\
\hline $\begin{array}{l}\text { Antipsychotic } \\
\text { administered }\end{array}$ & 2.39 & $(1.67,3.41)$ & $<0.0001$ \\
\hline Nasogastric tube & 2.03 & $(1.71,2.42)$ & $<0.0001$ \\
\hline $\begin{array}{l}\text { Benzodiazepine } \\
\text { administered }\end{array}$ & 1.55 & $(1.37,1.76)$ & $<0.0001$ \\
\hline Intravenous fluids & 1.80 & $(1.21,2.68)$ & 0.0039 \\
\hline Intensive care unit & 1.70 & $(1.16,2.50)$ & 0.0062 \\
\hline
\end{tabular}

${ }^{a}$ All models controlled for year of observation, intervention period, and presence of anxiety or agitation.

in the National Quality Forum consensus report on preferred practices for palliative care. ${ }^{39}$

Factors that were not associated with restraint use included palliative care consultation, an active order for opioid medication, and family presence. Our initial hypothesis was that these factors would have lessened restraint use. In the bivariate analysis, patients with a palliative care consultation were less likely to have physical restraints at end of life, but this association became nonsignificant in the multivariable analysis. This finding may encourage palliative care consultation teams to routinely review for restraint use and use this as an opportunity in consultation to stress alternative approaches to delirium prevention and management including discontinuing burdensome therapies, especially in the imminently dying patients. ${ }^{40}$

Regarding opioid use, the relationship between opioid medications and restraint use is not clearcut. For example, poor pain management can manifest as agitated behavior. ${ }^{41}$ However, it is also the case that opioids might be withheld in an effort to manage agitation for fear of worsening the behavior. The complexity of situations where opioids are provided or withheld at life's end can make it difficult to clarify any relationship that might exist between restraint use and opioid use.

The lack of association between family presence and restraint use was surprising. We expected that family members would find the use of restraints objectionable in a dying loved one and would advocate for their discontinuation. However, family members may not be empowered sufficiently to question medical and nursing interventions. The literature related to family response to restraint use is mixed. Some family members perceive restraint use as necessary and acceptable for care plan adherence. ${ }^{16,42}$ Family and provider education about alternatives to using restraints, such as discontinuing invasive interventions, may result in less restraint use at end of life.

Generalizability of these findings may be limited due to the disproportionately male sample and the unique VA culture and processes of care that may differ from other health systems with regard to the use of restraints. Furthermore, we were limited to variables collected in the parent study, and our examination of predictors of restraint use is not exhaustive. For example, nursing practices, staffing patterns, and training may have a significant influence on the use of physical restraints. We did not have access to these data. Finally, chart abstraction may underestimate the use of restraints, affecting our prevalence estimate, which may be higher than the $16.3 \%$ identified in this sample.

The evidence base does not currently support recommendations for systematic changes to reduce the use of restraints in dying patients. Data is limited that supports effectiveness of nursing education interventions to reduce restraint use in the acute care setting. ${ }^{43}$ One initial step, however, is to raise awareness of restraint use at the end of life as a negative outcome that may result from extending intensive life-supporting therapies.

\section{Conclusions}

This study highlights a number of issues meriting further investigation. As we seek to operationalize dying with dignity in the ICU or acute care setting, ${ }^{44}$ optimized end-of-life care would ensure comfort through active symptom identification and management, discontinuation of unhelpful therapies, and implementation of active management of terminal delirium without the need for the use of restraints. It is disconcerting that in this study more than one in six dying patients were restrained at the time of death. Our analysis, however, could not identify how frequently end-of-life restraint use may have been appropriate, necessary, and consistent with the patient/ health care agent's treatment goals. Guidelines and the literature underscore alternatives to restraint use in hospitals, particularly ICUs, and our findings suggest that dying patients are an important target population for the development of interventions and education to reduce restraint use.

\section{Acknowledgments}

This research was supported by a merit review grant from the Department of Veterans Affairs, Veterans Health Administration, Office of Research and Development, Health Services Research and Development Service (IIR 03-126 "Intervention to Improve Care at Life's End in VA Medical Centers;" PI: KL Burgio, Co-PI: FA Bailey) and the VA Birmingham/Atlanta Geriatric Research, Education and Clinical Center. Dr. DionneOdom is a postdoctoral fellow supported by the UAB Cancer Prevention and Control Training Program (5R25CA047888).

The authors thank the participating VA Medical Centers, their site principal investigators, and their palliative care teams for their roles in implementing the BEACON trial: Anna D. Senseney, MD and John Painter, PhD (site principal investigators), Karen Lukacs, RN, APN, and the palliative care team at the Ralph H. Johnson VAMC, Charleston, South Carolina; Theodore M. Johnson II, MD, MPH (site principal investigator), Adam Herman, MD, Orania Tigaieru, MD, Donna Lewis, CRNP, and the palliative care team at the Atlanta VAMC, Decatur, Georgia; Kathlyn Sue Haddock, $\mathrm{RN}, \mathrm{PhD}$ (site principal investigator), Debra Layer, CRNP, and the palliative care team at the William Jennings Bryan Dorn VAMC, Columbia, South Carolina; Thomas Hartney, MD (site principal investigator), Michael Willoughby, MD, and the palliative care team at the Charlie Norwood VAMC, Augusta Georgia; Leslie Pennypacker, MD (site principal investigator) and the palliative care team at the Malcom Randall VAMC, Gainesville, Florida; and Jessie Spencer, MD (site principal investigator) and the palliative care team at the G. V. Sonny Montgomery VAMC, Jackson, Mississippi.

\section{Author Disclosure Statement}

The views expressed in this article are those of the authors and do not necessarily reflect the position or policy of the Department of Veterans Affairs or the U.S. government.

No competing financial interests exist. 


\section{References}

1. Centers for Medicare and Medicaid Services, Department of Health and Human Services, Code of Federal Regulations, Title 42. Public Health. 482.13 Condition of participation: Patient's rights, pp. 2436.

2. Centers for Medicare and Medicaid Services, Department of Health and Human Services, Code of Federal Regulations, Title 42. Public Health. 482.13 Condition of Participation: Requirements 2433-2454 for, and assuring quality of care in, skilled nursing facilities. 2010:2433-2454.

3. Hamers JP, Huizing AR: Why do we use physical restraints in the elderly? Z Gerontol Geriatr 2005;38:19-25.

4. Pellfolk TJ, Gustafson Y, Bucht G, Karlsson S: Effects of a restraint minimization program on staff knowledge, attitudes, and practice: A cluster randomized trial. J Am Geriatr Soc 2010;58:62-69.

5. Capezuti E, Evans L, Strumpf N, Maislin G: Physical restraint use and falls in nursing home residents. J Am Geriatr Soc 1996;44:627-633.

6. Inouye SK, Zhang Y, Jones RN, et al.: Risk factors for delirium at discharge: Development and validation of a predictive model. Arch Intern Med 2007;167:1406-1413.

7. Werner P, Cohen-Mansfield J, Braun J, Marx MS: Physical restraints and agitation in nursing home residents. J Am Geriatr Soc 1989;37:1122-1126.

8. Castle NG, Engberg J: The health consequences of using physical restraints in nursing homes. Med Care 2009;47: 1164-1173.

9. Demir A: Nurses' use of physical restraints in four Turkish hospitals. J Nurs Scholarsh 2007;39:38-45.

10. Engberg J, Castle NG, McCaffrey D: Physical restraint initiation in nursing homes and subsequent resident health. Gerontologist 2008;48:442-452.

11. Kwok T, Bai X, Chui MY, et al.: Effect of physical restraint reduction on older patients' hospital length of stay. J Am Med Dir Assoc 2012;13:645-650.

12. Karger B, Fracasso T, Pfeiffer H: Fatalities related to medical restraint devices: Asphyxia is a common finding. Forensic Sci Int 2008;178:178-184.

13. McCabe DE, Alvarez CD, McNulty SR, Fitzpatrick JJ: Perceptions of physical restraints use in the elderly among registered nurses and nurse assistants in a single acute care hospital. Geriatr Nurs 2011;32:39-45.

14. Chuang YH, Huang HT: Nurses' feelings and thoughts about using physical restraints on hospitalized older patients. J Clin Nurs 2007; 16:486-494.

15. Minnick A, Leipzig RM, Johnson ME: Elderly patients' reports of physical restraint experiences in intensive care units. Am J Crit Care 2001;10:168-171.

16. Gallinagh R, Nevin R, Campbell L, et al.: Relatives' perceptions of side rail use on the older person in hospital. Br $\mathrm{J}$ Nurs 2001;10:391-392.

17. Fairman J, Happ MB: For their own good? A historical examination of restraint use. HEC forum: An interdisciplinary journal on hospitals' ethical and legal issues. HEC Forum 1998;10:290-299.

18. Frengley JD, Mion LC: Incidence of physical restraints on acute general medical wards. J Am Geriatr Soc 1986;34:565-568.

19. Goodlin SJ, Winzelberg GS, Teno JM, et al.: Death in the hospital. Arch Intern Med 1998;158:1570-1572.

20. Minnick AF, Mion LC, Johnson ME, et al.: Prevalence and variation of physical restraint use in acute care settings in the US. J Nurs Scholarsh 2007;39:30-37.
21. Bredthauer D, Becker C, Eichner B, et al.: Factors relating to the use of physical restraints in psychogeriatric care: A paradigm for elder abuse. Z Gerontol Geriatr 2005;38:10-18.

22. Meyer G, Kopke S, Haastert B, Muhlhauser I: Restraint use among nursing home residents: Cross-sectional study and prospective cohort study. J Clin Nurs 2009;18:981-990.

23. Martin B, Mathisen L: Use of physical restraints in adult critical care: A bicultural study. Am J Crit Care 2005;14:133-142.

24. Minnick AF, Fogg L, Mion LC, et al.: Resource clusters and variation in physical restraint use. J Nurs Scholarsh 2007;39:363-370.

25. Kruger C, Mayer H, Haastert B, Meyer G: Use of physical restraints in acute hospitals in Germany: A multi-centre cross-sectional study. Int J Nurs Stud 2013;50:1599-1606.

26. Angus DC, Barnato AE, Linde-Zwirble WT, et al.: Use of intensive care at the end of life in the United States: An epidemiologic study. Crit Care Med 2004;32:638-643.

27. Bailey FA, Williams BR, Woodby LL, et al.: Intervention to Improve Care at Life's End in Inpatient Settings: The BEACON Trial. J Gen Intern Med 2014;29:836-843.

28. Williams BR, Woodby LL, Bailey FA, Burgio KL: Formative evaluation of a multi-component, education-based intervention to improve processes of end-of-life care. Gerontol Geriatr Educ 2014;35:4-22.

29. Diggle PJ, Heagerty P, Liang KY, Zeger S: Analysis of Longitudinal Data. Oxford: Oxford University Press, 2013.

30. Fay MP, Graubard BI: Small-sample adjustments for Waldtype tests using sandwich estimators. Biometrics 2001;57: 1198-1206.

31. Mancl LA, DeRouen TA: A covariance estimator for GEE with improved small-sample properties. Biometrics 2001;57: 126-134.

32. Pan W, Wall MM: Small-sample adjustments in using the sandwich variance estimator in generalized estimating equations. Stat Med 2002;21:1429-1441.

33. Kauermann G, Carroll RJ: A Note on the efficiency of sandwich covariance matrix estimation. J Am Stat Assoc 2001;96:1387-1396.

34. Ciocon JO, Silverstone FA, Graver LM, Foley CJ: Tube feedings in elderly patients: Indications, benefits, and complications. Arch Intern Med 1988;148:429-433.

35. Panel AGSBCUE: American Geriatrics Society updated Beers Criteria for potentially inappropriate medication use in older adults. J Am Geriatr Soc 2012;60:616-631.

36. Lonergan E, Luxenberg J, Areosa Sastre A: Benzodiazepines for delirium. Cochrane Database Syst Rev 2009:CD006379.

37. Bush SH, Leonard MM, Agar M, et al.: End-of-life delirium: Issues regarding recognition, optimal management and the role of sedation in the dying phase. J Pain Symptom Manage 2014;48:215-230.

38. Clarke EB, Curtis JR, Luce JM, et al.: Quality indicators for end-of-life care in the intensive care unit. Crit Care Med 2003;31:2255-2262.

39. Mularski RA, Curtis JR, Billings JA, et al.: Proposed quality measures for palliative care in the critically ill: A consensus from the Robert Wood Johnson Foundation Critical Care Workgroup. Crit Care Med 2006;34:S404-S411.

40. Choosing Wisely, Five Things Physicians and Patients Should Question: Part 2. americangeriatric.org. (Last Accessed September 14, 2014.)

41. Cipher DJ, Clifford PA, Roper KD: Behavioral manifestations of pain in the demented elderly. J Am Med Dir Assoc 2006;7:355-365. 
42. Hardin SB, Magee R, Vinson MH, et al.: Patient and family perceptions of restraints. J Holist Nurs 1993;11: 383-397.

43. Said AA, Kautz DD: Reducing restraint use for older adults in acute care. Nursing 2013;43:59-61.

44. Cook D, Rocker G: Dying with dignity in the intensive care unit. N Engl J Med 2014;370:2506-2514.
Address correspondence to: Elizabeth Kvale, MD

University of Alabama at Birmingham CH19 Suite 301

Birmingham, AL 35294

E-mail: EKvale@uabmc.edu 